\title{
Reference values of Forced Expiratory Volumes and pulmonary flows in 3-6 year children: a cross-sectional study
} Pavilio Piccioni ${ }^{1}$, Alberto Borraccino*2, Maria Pia Forneris ${ }^{1}$, Enrica Migliore ${ }^{1}$, Carlo Carena ${ }^{3}$, Elisabetta Bignamini ${ }^{4}$, Stefania Fassio ${ }^{4}$, Giorgio Cordola ${ }^{4}$, Walter Arossa ${ }^{1}$ and Massimiliano Bugiani ${ }^{1}$

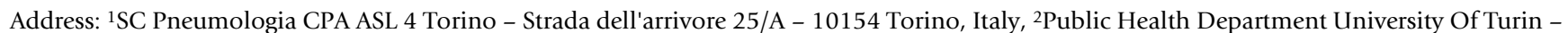
Via Santena 5bis - 10126 Torino, Italy, ${ }^{3}$ SSD Pediatria Osp G Bosco ASL 4 Torino - Piazza del Donatore di Sangue, 3 - 10154 Torino, Italy and ${ }^{4}$ SC Pneumologia ASO OIRM S. Anna Torino - Corso Spezia, 60 - 10126 Torino, Italy

Email: Pavilio Piccioni - ppiccioni@qubisoft.it; Alberto Borraccino* - alberto.borraccino@unito.it; Maria Pia Forneris - mariapiaforneris@hotmail.com; Enrica Migliore - enrica.migliore@cpo.it; Carlo Carena - carlocarena@aslto4.it; Elisabetta Bignamini - pneumoirm@oirmsantanna.piemonte.it; Stefania Fassio - pneumoirm@oirmsantanna.piemonte.it; Giorgio Cordola - pneumoirm@oirmsantanna.piemonte.it; Walter Arossa - warossa@qubisoft.it; Massimiliano Bugiani - mbugiani@qubisoft.it

* Corresponding author

Published: 22 February 2007

Respiratory Research 2007, 8:14 doi:10.1 186/1465-9921-8-14
Received: 16 October 2006

Accepted: 22 February 2007

This article is available from: http://respiratory-research.com/content/8/I/14

(c) 2007 Piccioni et al; licensee BioMed Central Ltd.

This is an Open Access article distributed under the terms of the Creative Commons Attribution License (http://creativecommons.org/licenses/by/2.0), which permits unrestricted use, distribution, and reproduction in any medium, provided the original work is properly cited.

\begin{abstract}
Background: The aims of this study were to verify the feasibility of respiratory function tests and to assess their validity in the diagnosis of respiratory disorders in young children.

Methods: We performed spirometry and collected information on health and parents' lifestyle on a sample of 960 children aged 3-6.

Results: The cooperation rate was $95.3 \%$. Among the valid tests, 3 or more acceptable curves were present in $93 \%$ of cases. The variability was $5 \%$ within subjects in $90.8 \%$ of cases in all the parameters. We propose regression equations for FVC (Forced Vital Capacity), FEVI, FEV0.5, FEV0.75 (Forced Expiratory Volume in one second, in half a second and in 3/4 of a second), and for Maximum Expiratory Flows at different lung volume levels (MEF75, 50, 25). All parameters are consistent with the main reference values reported in literature. The discriminating ability of respiratory parameters versus symptoms always shows a high specificity $(>95 \%)$ and a low sensitivity $(<20 \%)$ with the highest OR ( I0.55; IC95\% 4.42-25. 19) for MEF75. The ability of FEV0.75 to predict FEVI was higher than that of FEV0.50: FEV 0.75 predicts FEVI with a determination coefficient of 0.95 .

Conclusion: Our study confirms the feasibility of spirometry in young children; however some of the current standards are not well suited to this age group. Moreover, in this restricted age group the various reference values have similar behaviour.
\end{abstract}

\section{Background}

Lung disorders in children are quite common[1,2] and usually of an obstructive nature, generally confined to the intra-thoracic, intrapulmonary airways[3]. Reliable information on pulmonary function would aid the diagnostic process and patients' follow up. Studies on respiratory 
function tests concerning school children and adolescents have already been published $[4,5]$; and specific criteria for acceptance of maximal expiratory flow volume (MEFV) curves have also been proposed [5]. In recent times attention to this issue in pre-school children has increased $[3,6]$; different methods and means of measurement have been suggested, particularly spirometry $[5,7,8]$, whole body plethysmography [9], interrupter techniques $[10,11]$. With regard to spirometry, important studies assessing the feasibility and repeatability of the tests in preschool children have been conducted and have moreover demonstrated that many children are able to perform the required manoeuvres $[5,7,8,12-15]$. The latest guidelines on standardization of spirometry [16] emphasized that, with appropriate coaching, children as young as 5 years of age are often able to perform acceptable spirometry.

Infants and preschool children normally have large airways in relation to their lung volume [15], thus they empty their lungs more rapidly than older children and adults do. Therefore the forced expiratory volume in one second (FEV1) measurement may be difficult to achieve. Even when an FEV1 is available its clinical value remains questionable because it is often roughly equal to the forced vital capacity (FVC). As a consequence the FEV1/ FVC ratio results as being over $90 \%$ in the majority of the examined children [15]. In this case it may be more appropriate to report forced expiratory volume of $3 / 4$ of a second (FEV0.75), or FEV0.5 (forced expiratory volume of half a second) as a means for distinguishing abnormality in this age group $[13,15]$.

In cooperating subjects parameters from the descending part of a forced expiration manoeuvre have been proposed as useful indicators of airflow limitation [14].

Some studies conducted on healthy young children have proposed reference equations for FVC, FEV1 and for instantaneous expiratory flows [12-14], but only one of them has proposed reference values for FEV 0.5 [13], and none of the studies retrieved seems to have considered FEV0.75; furthermore none of these parameters have yet been validated with regard to FEV1 and disease or respiratory symptoms.

The aims of this study are twofold:

1) to produce reference values for VC, FEV (Forced Expiratory Volumes) at 1, 0.75 and 0.5 of a second, FEVt/FVC ratios and instantaneous expiratory flow (MEF) respectively for $75 \%, 50 \%$, and $25 \%$ of the expired FVC) for children between 3 and 5 years of age;
2) to discuss the accuracy[17] with which different pulmonary function parameters can distinguish between children with and without respiratory symptoms

\section{Materials and methods}

In 2002, in the context of a study regarding the effects of indoor and outdoor pollution on the respiratory tract, we carried out a survey on a sample of children aged 3-6 attending kindergartens in Turin. We selected 20 kindergartens among the ones located in an area of approximately 500 meters from the 20 air pollution monitoring sites.

A standardized questionnaire $[18,19]$ to be filled in by parents was given to all the children. The questionnaire investigates for the presence of a medical diagnosis of asthma and asthma-like symptoms (occurrence of wheezing and whistling when resting and under strenuous activity, shortness of breath, dry cough, phlegm and chest tightness), rhinitis (frequent sneezing, runny or blocked nose not connected with a cold or flu, itchy or watery eyes), any medical treatment and risk factors.

After the parents' prior approval, the spirometries were carried out in the morning during kindergarten activities; the children's height (measured with a stadiometer), weight and body mass index (BMI) (computed as weight/ height ${ }^{\wedge} 2$ ) were also recorded. Spirometry was performed with the turbine based Masterscope Rotary Jaeger. None of the children had ever performed spirometry in the past. To perform the spirometry, like in other studies $[12,13]$ the children were gathered into small groups and using playful communication we explained how to carry out the test. All the children tried a forced expiration before doing the real spirometry. The tests were done standing and with a nose clip. All the tests were performed using special incentive software ("blowing out candles software"). For the initial manoeuvres we encouraged the children to focus their attention on the computer screen: then they were invited to look at the operator's face and perform the manoeuvres together, blowing for as long as possible, and stopping at the operator's command.

The volume-time $(\mathrm{V}-\mathrm{T})$ and flow-volume $(\mathrm{F} / \mathrm{V})$ tracing obtained were visually inspected to assess the results. Children unable to perform any valid expiratory effort were considered to be non cooperating.

For each child a number of 3-6 MEFV curves were recorded within a 10-15 minute interval. Subjects with only one acceptable manoeuvre were not considered in the analysis.

We have considered not acceptable all the manoeuvres with: 
a) a sub-maximal expiratory effort in which a peak expiratory flow (PEF) was not clearly determined (i.e. in presence of flat or rounded curves) [12-15], or with slow rise of PEF (top of the curve to the right)[13];

b) evidence of cough or glottis closure $[13,15]$;

c) an expiration time lesser than 0.5 seconds[15];

d) an abrupt end of expiration effort (presence of a sharp drop or cessation in flow from a point in which the flows where $>25 \%$ of PEF) [12].

Children with reported skeletal anomalies or lung diseases, other than asthma, were also excluded.

Among all the acceptable subject curves, we considered in the analysis the ones with the largest sum of FVC and FEV1, FEV0.75 or FEV0.5 according to the maximum expiratory time obtained [20].

The instantaneous expiratory flow parameters, as well as those for the other parameters, were obtained from the best curve among the 3-6 attempts recorded and only when these were acceptable were they used for the analysis, in particular:

1. for FVC and MEF75-50-25 reference equations we considered only curves without any kind of early termination;

2. for FEV1, FEV0.75 and FEV0.5 reference equations we considered curves with flow expiration time (FET) respectively $\geq 1, \geq 0.75$ and $\geq 0.5$ of a second.

\section{Data analysis}

The absolute and the relative frequencies of non-cooperative subjects were computed and reported by sex and age; the effect of age and sex on cooperation was analyzed by means of logistic regression analysis using cooperation as dependent and age and sex and their interaction (if significant at the $5 \%$ level) as predictive variables. The relative and absolute frequencies of subjects according to the exclusion criteria and the number of acceptable manoeuvres performed were also computed and reported: each subject could have more than one cause of exclusion. The repeatability[21] of lung function parameters was evaluated by calculating the absolute difference between the largest value and the second largest value of each parameter (FVC, FEV1, FEV0.75, and FEV0.5) expressed as a percentage of the largest observed measure and reported by class $(0-5 \%, 5.1 \%-10 \%,>10 \%)$; the absolute difference between the two best FEV1 among the satisfactory manoeuvres was also computed and reported by class of $\mathrm{ml}(0-100,101-150,>150)$. All subsequent analyses were performed using only data from subjects satisfying the acceptability criteria for the parameter considered. Reference values were calculated on healthy children; all the subjects with at least one affirmative answer to the following were excluded:

- asthma during lifetime;

- presence of wheezing not connected with colds;

- a dyspnoea attack;

- chest tightening;

- taking drugs for asthma;

- presence of recurrent cough.

We performed a set of linear regression analyses using gender, age, body height, weight and BMI as predictive variables and lung function forced volumes at 1, 0.75, 0.5 seconds and FVC as dependent variables. The best transformation for each variable was selected with the Box-Cox method [22]. The best-fitting regression model was selected according to the likelihood ratio test [22]. Diagnostic tests for outliers and influential cases were performed and checked for consistency, and if inconsistent they were excluded.

In the presence of variables collinearity (i.e. height vs BMI or BMI vs weight) the one causing the smallest deviance reduction, when introduced into the model, was removed $[22,23]$.

The performance of a lung function variable to detect abnormally decreased airway function in symptomatic subjects was assessed by calculating the sensitivity and specificity for each symptom at the fifth percentile of the reference population, corresponding to a one tail $\mathrm{Z}$ score of -1.645 of the regression RSE. Cross tabulation was performed by normal/abnormal lung function parameters and by the presence or the absence of symptoms as previously defined. Odds Ratios (OR) of abnormal tests for symptomatic versus asymptomatic subjects were also computed for each lung function parameter in multiple logistic regression analysis, accounting for confounding effects.

We estimated the ability of FEV0.75 and FEV0.5 to predict FEV1 by means of linear regression using FEV1 as dependent and respectively FEV0.5 and FEV0.75 as predictive variables. In the case of perfect prediction we could expect a constant not different from 0 and a regression coefficient of 1 . 


\section{Results Quality controls}

In the 20 kindergartens a total of 1,249 children aged between 3 and 6 were involved in the study, and the parents' informed consent was retrieved for 1,020 children $(81.7 \%)$. Out of these, 56 children were absent during the days in which tests were carried out and 4 refused to undergo the lung examination. Spirometries were performed on a total of 960 children, with a cooperation rate of $95.3 \%$ ( 45 non cooperative children).

The cooperation rate (Table 1 ) was significantly higher in children older than 3 years of age (Chi-square 11.68, p < 0.01 ) with not significant differences between genders (Chi-square 0.37, p >0.10).

Among the 915 cooperative subjects, 149 (16.3\%) tests results were excluded as they lacked one or more of the acceptability criteria (Table 2): a total of 766 (83.7\%) tests results were included for the analysis.

No age nor gender distribution differences were found either in the included or in the excluded subjects ( $\mathrm{p}<$ $0.05)$. Three or more acceptable curves, resulting from the validity test, were present in 93\% of cases. The frequency of exclusion, among the 3-year old children, was higher but not statistically significant.

The whole group Flow Expiration Time (FET) mean was 1.1 seconds (IC 95\% 1.07-1.13) with non significant gender and age variation.

Among the 766 tests included for further analysis, we observed in 278 cases an early termination with the presence of a sharp drop or a cessation in flow from a point in which the flows where $<25 \%$ of PEF. These 278 subjects were considered only for their $\mathrm{FEV}_{0.5}, \mathrm{FEV}_{0.75}$ and $\mathrm{FEV}_{1}$ and not for FVC and flow analysis (see tab3).
The repeatability of FVC and FEVt for all the parameters was fairly good, with a variability $=10 \%$ for almost all the children (higher than 99\%) and within 5\% in $90.8 \%$ of cases: the absolute variability among the different manoeuvres of the same subjects was under $100 \mathrm{ml}$ for $98.6 \%$ of subjects, and under $150 \mathrm{ml}$ for all subjects. The MEF25, MEF50 and MEF75 repeatability was lower than the volumes repeatability. Among flows, MEF75 had the smallest variability ( $<=10 \%$ for $84.4 \%$ of subjects) (Table 3).

\section{Reference values}

Table 4 reports the anthropometric characteristics of the 766 subjects. The girls were slightly taller and heavier than the boys. The $5^{\text {th }}$ and $95^{\text {th }}$ BMI percentile (mean \pm 1.64 standard deviations) were respectively 12.6 and 18.8 over all (12.9 and 19.1 for females; 12.4 and 18.4 for males), within the normal range reported in literature for these ages $[18,19]$.

Table 5 reports the lung function parameter means and standard deviations by symptom status. In asymptomatic subjects the lung function parameter values were slightly higher than those in symptomatic subjects. The Box-Cox test[22] for regression analysis of the lung function parameters versus anthropometric variables showed that no linear transformation of dependent or independent variables was necessary. Among asymptomatic subjects the multiple regression analysis (Table 6), using gender, age, height and BMI as covariates, demonstrated that the static and the dynamic lung volumes were significantly higher in females than in males. A significant age positive effect was detected for all lung volumes except for FVC and FEV1. A significant positive effect was also detected for all lung volumes which was independent from height and BMI. Body weight was collinear (Variance Inflation Factor, VIF >18) with BMI and it was therefore excluded on the basis of the Likelihood Ratio (LR)[22] test ( $\mathrm{p}=$ 0.09 for weight $\mathrm{p}=0.04$ for $\mathrm{BMI}$ ).

Table I: Number and proportion of non cooperating subjects at the spirometry tests, divided according to age and sex

\begin{tabular}{|c|c|c|c|c|c|c|c|c|c|}
\hline \multirow{3}{*}{ Age (yrs) } & \multicolumn{3}{|c|}{ Females } & \multicolumn{3}{|c|}{ Males } & \multicolumn{3}{|c|}{ Total } \\
\hline & \multirow[t]{2}{*}{ Total } & \multicolumn{2}{|c|}{$\begin{array}{c}\text { Non } \\
\text { cooperating }\end{array}$} & \multirow[t]{2}{*}{ Total } & \multicolumn{2}{|c|}{$\begin{array}{c}\text { Non } \\
\text { cooperating }\end{array}$} & \multirow[t]{2}{*}{ Total } & \multicolumn{2}{|c|}{$\begin{array}{c}\text { Non } \\
\text { cooperating }\end{array}$} \\
\hline & & $N$ & $\%$ & & $N$ & $\%$ & & $N$ & $\%$ \\
\hline 3 & 20 & 2 & 10.0 & 29 & 6 & 20.7 & 49 & 8 & $16.3^{*}$ \\
\hline 4 & 204 & 9 & 4.4 & 230 & 12 & 5.2 & 434 & 21 & 4.8 \\
\hline 5 & 200 & 6 & 3.0 & 222 & 8 & 3.6 & 422 & 14 & 3.3 \\
\hline 6 & 20 & 1 & 5.0 & 35 & 1 & 2.8 & 55 & 2 & 3.6 \\
\hline Tot & 450 & 18 & 4.0 & 509 & 27 & 5.3 & 960 & 45 & 4.7 \\
\hline
\end{tabular}

$* \chi^{2}=11.68, p<0.01$ 
Table 2: Numbers and percentage of excluded subjects by exclusion criteria and number of acceptable tests

\begin{tabular}{lcc}
\hline Exclusion criteria and acceptable test & $\mathrm{N}$ & $\%$ \\
\hline Curves with a sub-maximal expiratory effort & 56 & 6.1 \\
Only I acceptable manoeuvre & 4 & 0.4 \\
Early interruption & 100 & 10.9 \\
Expiration time $<0.5 \mathrm{sec}$ & 7 & 0.8 \\
\hline Total excluded subjects & 149 & 16.3 \\
Subjects with acceptable tests & 766 & 83.7 \\
\hline
\end{tabular}

Among instantaneous maximum expiratory flows, also shown in Table 6, MEF75 increases with age, height and BMI and decreases, but without statistical significance, with weight with a $\mathrm{R}^{\wedge} 2$ of 0.41 ; MEF50 and MEF25 increase significantly only with height. $\left(\mathrm{R}^{\wedge} 2=0.29\right.$ for MEF50 and 0.19 for MEF25). Because of the little and not significant effect shown, the age, the weight and the BMI were excluded from the final model.

The regression of volume time, expressed as an FVC fraction, versus anthropometric variables did not show any significant effect: a poor height effect gave a determination coefficient that is lower than $4 \%$. The values were distributed asymmetrically and no linear transformation was able to correct for the absence of normality [22]. The lower normality limits were computed as the $5^{\text {th }}$ percentile of non parametric distribution in asymptomatic children (Table 7).

\section{Validation of reference values}

The test sensitivity and its specificity versus symptoms in children with a reduced function parameter are reported in Figure 1. These were computed as the observed value, lower than predicted, minus 1.64 regression standard error (RSE) for FVC, FEVt and MEFx, and lower than the $5^{\text {th }}$ percentile for $\mathrm{FEVt} / \mathrm{FVC} \%$.

The sensitivity and specificity are comparable among all the recorded parameters: MEF75 showed the highest sensitivity $(18.8 \%)$ with a specificity of $97.9 \%$ and a combination (ROC Receiver Operating Characteristic) of 58\%; FVC showed the worst sensitivity $(4.2 \%)$ and the best specificity $(98.9 \%)$.

In Table 8 we reported the strength of association, expressed as OR, between symptom status and lung function normality parameters, adjusted for age, sex and anthropometric variables. Each given parameter, except for the FEV1/FVC\% ratio, was significantly associated with symptoms. MEF75 and FEV1 showed the higher association with an OR respectively of 10.6 and 4.2.

\section{Relationship between volumes/time measurements}

The regression equations were calculated using FEV1 as dependent variable and respectively FEV0.75 and FEV0.5 as predictive, and using FEV0.75 as dependent and FEV0.5 as predictive variable (Table 9). The FEV0.75 showed to be suitable to predicts FEV1 quite well, with a 0.95 of determination coefficient: FEV1 is expected to increase by 1.06 litres for each litre of increase in FEV0.75 with an intercept nearly equal to 0 . The FEV1 prediction, by using the measured FEV0.5, is less precise than using the FEV0.75 with a 44 millilitres of systematic difference (intercept): FEV1 is expected to increase by 1.166 litres. For every increase of 1 litre in FEV0.5, the determination coefficient resulted to be 0.87 .

\section{Discussion Quality control}

In this study spirometries in young children were analyzed to determine whether they met the published qual-

Table 3: Repeatability within subject of lung function parameters expressed as within subjects variation coefficient (standard deviation within the two best/mean of the two best\%)

\begin{tabular}{lccccccc}
\hline & $\mathrm{FVCa}$ & $\mathrm{FEV}, \mathrm{b}$ & $\mathrm{FEV}_{0.75}{ }^{\mathrm{c}}$ & $\mathrm{FEV}_{0.5}{ }^{\mathrm{d}}$ & $\mathrm{MEF}_{75}{ }^{\mathrm{e}}$ & $\mathrm{MEF}_{50} \mathrm{f}^{2}$ & $\mathrm{MEF}_{25} \mathrm{~g}$ \\
\hline $\mathrm{N}$ & 458 & 576 & 680 & 766 & 458 & 458 & 458 \\
Mean (\%) & 2.0 & 2.2 & 2.2 & 2.1 & 6.0 & 9.1 & 16.3 \\
$\operatorname{Max}(\%)$ & 12.4 & 13.6 & 13.7 & 14.1 & 51.9 & 51.9 & 92.3 \\
$0-5 \%(\%)$ & 90.8 & 90.8 & 92.1 & 90.9 & 65.0 & 41.1 & 23.9 \\
$6-10 \%(\%)$ & 8.1 & 8.5 & 7.5 & 8.4 & 19.4 & 33.5 & 20.2 \\
$10 \%+(\%)$ & 1.1 & 0.7 & 0.4 & 0.8 & 15.6 & 25.3 & 56.0 \\
\hline
\end{tabular}

aFVC $=$ forced vital capacity;

${ }^{\mathrm{b} F E V}$ = forced expiratory volume in one second;

${ }^{c} \mathrm{FEV}_{0.75}=$ forced expiratory volume in $3 / 4$ of a second;

${ }^{d} \mathrm{FEV}_{0.5}=$ forced expiratory volume in half a second;

eMEF $_{75}=$ instantaneous expiratory flow when $25 \%$ of $\mathrm{FVC}$ has to be expired

$\mathrm{fMEF}_{50}=$ instantaneous expiratory flow when $50 \%$ of $\mathrm{FVC}$ has to be expired

$\mathrm{gMEF}_{25}=$ instantaneous expiratory flow when $75 \%$ of $\mathrm{FVC}$ has to be expired 
Table 4: Characteristics (mean and standard deviation) of the $\mathbf{7 6 6}$ subjects considered for estimation and validation of the reference values

\begin{tabular}{|c|c|c|c|c|c|}
\hline Gender & Age (yrs) & $\mathrm{N}$ & Height $(\mathrm{cm}) \mathrm{m}(\mathrm{sd}) \S$ & Weight $(\mathrm{kg}) \mathrm{m}(\mathrm{sd}) \S$ & $\mathrm{BMI} * \mathrm{~m}(s d) \S$ \\
\hline \multirow[t]{5}{*}{ Males } & 3 & 19 & $104.6(3.5)$ & $16.3(1.9)$ & $14.9(1.5)$ \\
\hline & 4 & 181 & $107.3(4.9)$ & $17.8(2.6)$ & $15.4(I .8)$ \\
\hline & 5 & 177 & I I 3.3 (4.6) & $19.9(2.8)$ & $15.4(1.8)$ \\
\hline & 6 & 29 & I I 8.7 (5.5) & $22.9(4.2)$ & $16.2(2.2)$ \\
\hline & Total & 406 & I I 0.5(5.9) & 18.9 (3.1) & I 5.4 (I.8) \\
\hline \multirow[t]{5}{*}{ Females } & 3 & 15 & $105.1(4.4)$ & $17.9(1.8)$ & $16.2(1.2)$ \\
\hline & 4 & 163 & $108.9(4.7)$ & $18.7(2.5)$ & $15.7(I .7)$ \\
\hline & 5 & 162 & II 4.7 (5.5) & 21.1 (3.7) & $16.0(2 . I)$ \\
\hline & 6 & 20 & I $19.3(5.7)$ & $24.3(6.0)$ & $17.0(3.3)$ \\
\hline & Total & 360 & I I $2.0(5.6)$ & $20.1(3.0)$ & $16.0(1.9)$ \\
\hline \multirow[t]{5}{*}{ Whole group } & 3 & 34 & $104.9(4.0)$ & 17.4 (I.9) & I5.8 (I.4) \\
\hline & 4 & 344 & $108.2(4.9)$ & $18.3(2.6)$ & $15.6(1.8)$ \\
\hline & 5 & 329 & $114.0(5.1)$ & $20.5(3.4)$ & $15.7(2.0)$ \\
\hline & 6 & 49 & $119.1(5.6)$ & $23.8(5.4)$ & $16.7(2.9)$ \\
\hline & Total & 766 & 111.3 (6.2) & $19.6(3.5)$ & I5.7(I.9) \\
\hline
\end{tabular}

$* \mathrm{BMI}=$ Body Mass Index

$\S \mathrm{m}(s d)=$ mean (standard deviation)

ity control criteria and to examine the possible differences.

A more recent guideline[16] has marginally discussed the issues peculiar to spirometric examination in young children and it says that the examination is considered just as feasible in this age group as it is in adults; indices derived from blowing and recording the expiratory times of $<1$ second were considered to have clinical usefulness. However, the data shown for recommending the use of FEV0.5 and FEV0.75 for clinical purposes were insufficient. Furthermore, in the criteria to evaluate the duration of the test, these guidelines recommend that "the V-T curve shows no changes for $=1$ second and the subject tries to exhale for $\geq$ 3 seconds in children aged $<10$ years" [16], without any additional specification.

This study confirms the feasibility of spirometric examinations in symptomatic or asymptomatic young children, but our results suggest that, because of the too short expiration time, the last guideline indication is not applicable in children younger than 6 . The mean FET observed in our children were all around 1 second.

In 3-year-old subjects the cooperation rate was low $(83.7 \%)$ but high enough to justify the use of spirometry

Table 5: Distribution (mean and standard deviation) of lung function parameter by symptom status

\begin{tabular}{|c|c|c|c|c|c|c|}
\hline & \multicolumn{2}{|c|}{ Asymptomatic } & \multicolumn{2}{|c|}{ Symptomatic } & \multicolumn{2}{|c|}{ Total } \\
\hline & $\mathrm{N}$ & $\mathrm{m}(\mathrm{sd}) \S$ & $\mathrm{N}$ & $\mathrm{m}(s d) \S$ & $\mathrm{N}$ & $\mathrm{m}(\mathrm{sd}) \S$ \\
\hline $\mathrm{FVC}(\mathrm{It})^{\mathrm{a}}$ & 327 & $1.10(0.22)$ & 128 & $1.07(0.24)$ & 455 & $1.09(0.23)$ \\
\hline $\mathrm{FEV}_{1}(\mathrm{It})^{\mathrm{b}}$ & 409 & $1.09(0.20)$ & 169 & $1.05(0.21)$ & 578 & $1.08(0.21)$ \\
\hline $\mathrm{FEV}_{0.75}(\mathrm{It})^{\mathrm{d}}$ & 493 & $1.04(0.19)$ & 190 & $0.98(0.19)$ & 683 & $1.02(0.19)$ \\
\hline $\mathrm{FEV}_{0.5}(\mathrm{It})^{\mathrm{c}}$ & 562 & $0.90(0.16)$ & 205 & $0.86(0.16)$ & 767 & $0.89(0.16)$ \\
\hline $\mathrm{FEV}_{1} / \mathrm{FVC}$ & 285 & $0.96(0.04)$ & 116 & $0.96(0.04)$ & 401 & $0.96(0.04)$ \\
\hline $\mathrm{FEV}_{0.75} / \mathrm{FVC}$ & 311 & $0.92(0.05)$ & 123 & $0.91(0.07)$ & 434 & $0.92(0.06)$ \\
\hline $\mathrm{FEV}_{0.5} / \mathrm{FVC}$ & 327 & $0.81(0.07)$ & 128 & $0.80(0.09)$ & 455 & $0.81(0.08)$ \\
\hline $\mathrm{MEF}_{75}(\mathrm{It} / \mathrm{s})^{\mathrm{e}}$ & 327 & $2.32(0.50)$ & 128 & $2.18(0.53)$ & 455 & $2.28(0.5 I)$ \\
\hline $\operatorname{MEF}_{50}(\mathrm{It} / \mathrm{s})^{f}$ & 327 & $1.66(0.38)$ & 128 & $1.57(0.40)$ & 455 & $1.64(0.39)$ \\
\hline $\operatorname{MEF}_{25}(1 \mathrm{t} / \mathrm{s})^{\mathrm{g}}$ & 327 & $0.85(0.24)$ & 128 & $0.82(0.28)$ & 455 & $0.84(0.25)$ \\
\hline
\end{tabular}

$\S \mathrm{m}(\mathrm{sd})=$ mean $($ standard deviation $)$

aFVC = forced vital capacity;

${ }^{\mathrm{bFEV}}=$ forced expiratory volume in one second;

$\mathrm{CFEV}_{0.75}=$ forced expiratory volume in $3 / 4$ of a second;

${ }^{\mathrm{d}} \mathrm{FEV} . .5=$ forced expiratory volume in half a second;

$\mathrm{eMEF}_{75}=$ instantaneous expiratory flow when $25 \%$ of $\mathrm{FVC}$ has to be expired

$\mathrm{fMEF}_{50}=$ instantaneous expiratory flow when $50 \%$ of $\mathrm{FVC}$ has to be expired

$\mathrm{gMEF}_{25}=$ instantaneous expiratory flow when $75 \%$ of $\mathrm{FVC}$ has to be expired 
Table 6: Multiple regression coefficients $(\beta)$ of the lung function parameters $(Y) *$ versus anthropometric variables (in asymptomatic subjects)(x)

\begin{tabular}{|c|c|c|c|c|c|c|c|c|c|}
\hline $\begin{array}{l}\text { Lung } \\
\text { function } \\
\text { parameters }\end{array}$ & Sex (males) & Age (years) & Height (cm) & BMI (\%) & Weight (Kg) & Costant & $N$ & $\mathrm{R}^{\wedge} 2$ & RSE \\
\hline FVC & $-0.049 b$ & 0.018 & $0.026 c$ & $0.015^{c}$ & {$[0.01 \mathrm{I}]$} & $-2.042^{c}$ & 328 & 0.57 & 0.15 \\
\hline $\mathrm{FEV}_{\text {, }}$ & $-0.042^{b}$ & 0.038 & $0.023^{c}$ & $0.017 c$ & {$[0.013]$} & $-1.907 c$ & 409 & 0.59 & 0.13 \\
\hline $\mathrm{FEV}_{0.75}$ & $-0.034 c$ & $0.023^{b}$ & $0.022^{c}$ & $0.015^{b}$ & {$[0.008]$} & $-1.729 c$ & 494 & 0.59 & 0.12 \\
\hline $\mathrm{FEV}_{0.5}$ & $-0.03 I^{c}$ & $0.024^{b}$ & $0.017^{c}$ & $0.011^{b}$ & {$[0.001]$} & $-|.3| \mid c$ & 564 & 0.55 & 0.11 \\
\hline $\mathrm{MEF}_{75}$ & 0.059 & $0.108^{b}$ & $0.046^{c}$ & $0.024^{c}$ & {$[-0.113]$} & $-3.385^{c}$ & 328 & 0.41 & 0.39 \\
\hline $\mathrm{MEF}_{50}$ & 0.002 & {$[0.024]$} & $0.033^{c}$ & {$[0.015]$} & {$[-0574]$} & $-2.269^{c}$ & 328 & 0.29 & 0.32 \\
\hline MEF $_{25}$ & 0.012 & {$[-0.005]$} & $0.018^{c}$ & {$[0.075]$} & {$[-0.538]$} & $-1.152^{c}$ & 328 & 0.19 & 0.22 \\
\hline
\end{tabular}

$\mathrm{a}=\mathrm{p}<0.05 ; \mathrm{b}=\mathrm{p}<0.01 ; \mathrm{c}=\mathrm{p}<0.001 ;$

$\mathrm{BMI}=$ body mass index;

$\beta=$ Multiple Regression Coefficient;

FVC = forced vital capacity;

$F E V_{1}=$ forced expiratory volume in one second;

$\mathrm{FEV}_{0.75}=$ forced expiratory volume in $3 / 4$ of a second;

$\mathrm{FEV}_{0.5}=$ forced expiratory volume in half a second;

$\mathrm{MEF}_{75}=$ instantaneous expiratory flow when $25 \%$ of $\mathrm{FVC}$ has to be expired

$\mathrm{MEF}_{50}=$ instantaneous expiratory flow when $50 \%$ of $\mathrm{FVC}$ has to be expired

$\mathrm{MEF}_{25}=$ instantaneous expiratory flow when $75 \%$ of $\mathrm{FVC}$ has to be expired

[ ] brackets variables = excluded by log-likelihood ratio test because collinear or NS and not influent.

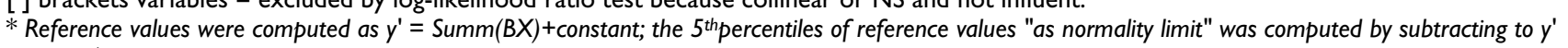

the $1.64 *$ Root MSE

in this age group; in children over 3 years of age the cooperation increases and the success rate becomes comparable to that of other studies based on samples of the general population $[7,8,12-14]$.

A lower success rate was reported in studies conducted on patients with respiratory diseases or in the case of very restrictive exclusion criteria [15]. Moreover, we obtained tests with at least 3 acceptable curves and with a variability among the requested manoeuvres lower than $10 \%$ in almost all of the cooperative children.

A critical problem observed in our sample concerns the early termination of many tests; it could be partly explained in relation to the psychomotor maturation of children in which there is an early realization of an equal pressure point at a point less close to the distal airways [4,24-26].

Nevertheless, in many cases early termination may be influenced by methodological or software issues as well $[27,28]$. A limit of our study is to be discussed in the incentive software used. The candle blowing incentive software produced by Jaeger is a good tool for early training or for encouraging peak flow manoeuvres, but it is less suitable when a full forced expiration is required $[15,27]$. This problem was addressed and partly limited by using an interactive procedure to perform the test: the children were requested to imitate and reproduce the operator's manoeuvres. Tests with an abrupt cessation of expiration need to be analyzed with caution. Due to lack of consensus on exclusion criteria[12,27,29], the choice of setting a cut-off of $25 \%$ of the PEF was done in order to balance the opposing requirements of having the best quality control and recording the largest quantity possible of useful information. Early termination should be quantified and pointed out in the lung function tests reports and, when it occurs, FEVt/FVC and MEFX parameters might not be registered.

With regard to quality control and acceptance criteria, in agreement with other authors [15], a realistic approach

Table 7: Mean and $5^{\text {th }}$ percentile as limit of normal value in asymptomatic subjects

\begin{tabular}{llll}
\hline Parameter & $\mathrm{N}$ & Mean & $5^{\text {th }}$ ntil \\
\hline $\mathrm{FEV}_{1} / \mathrm{FVC}$ & 285 & 0.96 & 0.88 \\
$\mathrm{FEV}_{0.75} / \mathrm{FVC}$ & $31 \mathrm{I}$ & 0.92 & 0.83 \\
$\mathrm{FEV}_{0.5} / \mathrm{FVC}$ & 327 & 0.81 & 0.69 \\
\hline
\end{tabular}

$\mathrm{FEV} / \mathrm{FVC}=$ ratio of forced expiratory volume in one second and forced vital capacity;

$\mathrm{FEV}_{0.75} / \mathrm{FVC}=$ ratio of forced expiratory volume in $3 / 4$ of a second and forced vital capacity;

$\mathrm{FEV}_{0.5} / \mathrm{FVC}=$ ratio of forced expiratory volume in half a second and forced vital capacity; 


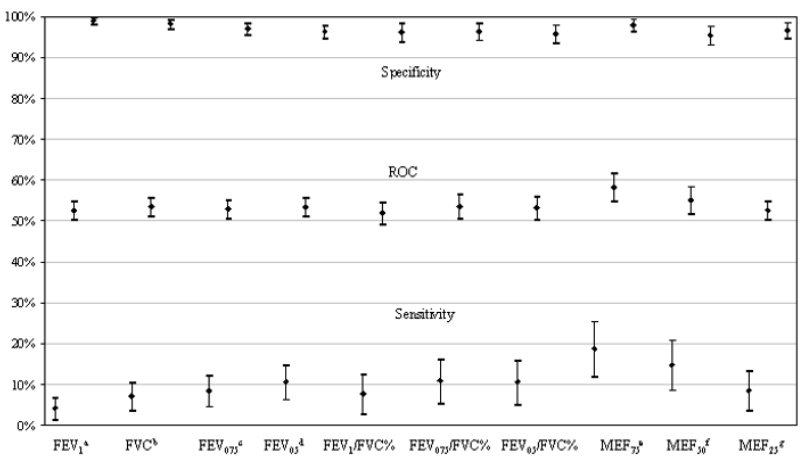

\section{Figure I}

Sensitivity and specificity (and $\mathrm{Cl} 95 \%$ ) versus symptoms in children of reduced function parameters. ROC $=$ Receiver Operating Characteristic. ${ }^{\text {aFVC }}=$ forced vital capacity; $\mathrm{bFEV}_{1}=$ forced expiratory volume in one second; $\mathrm{CFEV}_{0.75}=$ forced expiratory volume in $3 / 4$ of a second; ${ }^{d} \mathrm{FEV}_{0.5}=$ forced expiratory volume in half a second; eMEF $_{75}=$ instantaneous expiratory flow when $25 \%$ of $\mathrm{FVC}$ has to be expired. $\mathrm{fMEF}_{50}=$ instantaneous expiratory flow when $50 \%$ of FVC has to be expired. $8 \mathrm{MEF}_{25}=$ instantaneous expiratory flow when $75 \%$ of FVC has to be expired

could be that of accepting tests with at least 2 curves of maximum effort (PEF easily observable) and with a difference among parameters within $100 \mathrm{ml}(10 \%$ of FVC in our sample), to exclude tests lasting less than 0.5 seconds and to accept tests with small early interruptions of expiration.

\section{Reference equations}

Using the previously discussed quality control criteria we were able to propose the first reference equation for FEV0.75 (as far as we know) and new reference values for FVC, FEV1, FEV0.5 and for instantaneous expiratory flows (MEF75-MEF50-MEF25) based on a large sample of young children.

The increase of lung volumes with BMI, accounting for height, age and gender, reflects the effect of body size [13]or physical fitness[30,31]; although obesity is reported to determine a reduction of lung function values[32], this is not proved in our sample due to the BMI being within normal ranges in more than $95 \%$ of the population studied. Body weight seems to have a less important effect when controlling for the BMI.

The lack of a significant effect of age on FVC is probably due to the small size of the sample with an acceptable FVC measurement and to the limited age range in our study: in any case, we observed an increase in dynamic volumes of $23 \mathrm{ml}$ in FEV1 and of $15 \mathrm{ml}$ in FEV0.75 for each year of age increase.

About the gender effect found in our study, it is known that girls have better physiological performances than males in preadolescence[13,33]: the lack of any significant effect described in other studies on young children is probably the consequence of a lower statistical power[12]. Concerning the validity of reference values, studies con-

Table 8: Odds ratios (OR) of lung function parameters lower than $5^{\text {th }}$ percentile of reference value versus symptoms using "list-wise deletion"* of missing values and a single parameter

\begin{tabular}{lccc}
\hline Parameter & OR & Cl 95\% & $p$ value \\
\hline FVC & 4.05 & $1.41-11.61$ & 0.009 \\
FEV & 4.17 & $1.85-9.39$ & 0.001 \\
FEV $_{075}$ & 2.93 & $1.48-5.82$ & 0.002 \\
FEV $_{0.5}$ & 3.10 & $1.66-5.76$ & 0.000 \\
FEV $_{1} / \mathrm{FVC}$ & 2.10 & $0.84-5.20$ & 0.111 \\
$\mathrm{FEV}_{0.5} / \mathrm{FVC}$ & 3.22 & $1.45-7.18$ & 0.004 \\
$\mathrm{FEV}_{0.75} / \mathrm{FVC}$ & 2.71 & $1.22-6.02$ & 0.015 \\
$\mathrm{MEF}_{75}$ & 10.55 & $4.42-25.19$ & 0.000 \\
$\mathrm{MEF}_{50}$ & 3.63 & $1.78-7.38$ & 0.000 \\
$\mathrm{MEF}_{25}$ & 2.70 & $1.14-6.40$ & 0.024
\end{tabular}

* The single case is eliminated for the variable in which a missing value is present

$\mathrm{FVC}=$ forced vital capacity;

$\mathrm{FEV}_{1}=$ forced expiratory volume in one second;

$\mathrm{FEV}_{0.75}$ = forced expiratory volume in $3 / 4$ of a second;

$\mathrm{FEV}_{0.5}=$ forced expiratory volume in half a second;

$\mathrm{MEF}_{75}=$ instantaneous expiratory flow when $25 \%$ of $\mathrm{FVC}$ has to be expired

$\mathrm{MEF}_{50}=$ instantaneous expiratory flow when $50 \%$ of $\mathrm{FVC}$ has to be expired

$\mathrm{MEF}_{25}=$ instantaneous expiratory flow when $75 \%$ of $\mathrm{FVC}$ has to be expired 
Table 9: Regression equation using $\mathrm{FEV}_{1}$ as dependent variable and respectively $\mathrm{FEV}_{0.75}$ and $\mathrm{FEV}_{0.5}$ as predictive

\begin{tabular}{lccccc}
\hline Parameter & $\beta$ & $\mathrm{Cl} 95 \%$ & $\mathrm{a}$ & $\mathrm{Cl} 95 \%$ & $\mathrm{R} 2$ \\
\hline $\mathrm{FEV}_{0.75}$ & 1.06 & $(+1.04 ;+1.08)$ & -0.01 & $(-0.02 ;+0.02)$ & 0.950 \\
$\mathrm{FEV}_{0.5}$ & 1.17 & $(+1.13 ;+1.21)$ & 0.04 & $(+0.01 ;+0.08)$ & 0.870 \\
\hline
\end{tabular}

$\mathrm{R}^{2}=$ determination coefficient (proportion of explained variance);

$\mathrm{a}=$ intercept or constant and $\beta=$ regression coefficient;

$\mathrm{FEV}_{0.75}=$ forced expiratory volume in $3 / 4$ of a second;

$\mathrm{FEV}_{0.5}=$ forced expiratory volume in half a second.

ducted on infants $[25,26]$ suggest that flows have a better discriminative power versus symptoms than timed volumes can have. In young children FEVt (particularly FEV0.75 and FEV0.5) are certainly easier to achieve than forced expiratory flows are, furthermore these also have a higher repeatability.

Symptomatic subjects have a more elevated occurrence of functional alterations when compared to asymptomatic ones, nevertheless the test's sensitivity here is far from optimal. In fact, as normally to be expected in the young, children are usually defined as symptomatic on the basis of symptoms in the last 12 months reported by parents in the questionnaires. Hence, measurements often occur in a symptom-free period $[13,34,35]$.

The 95\% specificity, for asymptomatic children, is expected by definition using regression methods to calculate reference values. MEF75 and, secondarily, FEV1, versus symptoms, seems to be the parameter with the best sensitivity/specificity combination and the best discriminating ability; the FEV0.75 or the FEV0.5 should be considered to be adequate to be used when FEV1 was not obtained or its validity is under discussion (e.g. because of a too short expiratory time). To confirm the previous sentence it would be necessary to show that, particularly for this age group, the forced volumes expired in a time of shorter than 1 second is able to discriminate between healthy and diseased equally, or even better, than FEV1 is able to do: nevertheless this issue can be better resolved in a well designed case-reference or longitudinal cohort study but this is beyond the scope of the current study design.

The physiological implications of the different timed forced expiratory are as yet not well understood. Similarly to other studies on pulmonary flows in young children we observed that the FEV1 is rarely obtainable and, when retrieved, it is somewhat identical to the FVC. Our results showed that the FEV1, when absent or not reliable, could be estimated from $\mathrm{FEV}_{0.75}$ applying the corrections emerged (see Table 6). The corrected $\mathrm{FEV}_{0.75}$ could be considered a reliable proxy of the FEV1 to be used in those epidemiological studies in which emerge the need to compare flux parameters results in different age strata.
In conclusion, reproducible spirometry can be obtained in the majority of young children aged between 3 and 6 years old. Performing spirometry and using all measurable parameters in this age group has the potential to improve the assessment and the management of pulmonary diseases. In particular the forced expiratory volumes in less than 1 second may provide useful clinical information. It is recommended that such parameters should be collected in young children performing spirometry and further studied for their physiological and clinical significance.

\section{Competing interests}

The author(s) declare that they have no competing interests.

\section{Authors' contributions}

All of the authors have participated sufficiently in the work to take public responsibility for the whole content of it; in particular the following made substantial contributions to the intellectual content as described below:

PP contributed substantially for the conception and design and the drafting of the manuscript; $\mathrm{AB}$ contributed for the critical revision of the manuscript and for important intellectual content; MPF contributed to the drafting of the manuscript; EM contributed in the analysis and interpretation of data; CC contributed to the acquisition of data, technical, and material support; EB contributed to the acquisition of data, technical, and material support; SF contributed to the acquisition of data, technical, and material support; GC contributed to the acquisition of data, technical, and material support; WA contributed obtaining funding, technical, and material support and $\mathrm{MB}$ contributed substantially for obtaining funding, the supervision and the critical revision of the manuscript, for important intellectual content

\section{Grants}

This study was supported by a grant from the Region Piedmont, Italy

\section{Acknowledgements}

We wish to thank Riccardo Pellegrino for his help and precious advice and Susan Phillips for the English language revision 


\section{References}

I. Kozyrskyj AL, Mustard CA, Becker AB: Childhood wheezing syndromes and healthcare data. Pediatr Pulmonol 2003, 36: | 3|- 136.

2. Nja F, Nystad W, Hetlevik O, Lodrup Carlsen KC, Carlsen KH: Airway infections in infancy and the presence of allergy and asthma in school age children. Arch Dis Child 2003, 88:566-569.

3. P.J.F.M.Merkus, J.Stocks, Jongste JC: Respiratory function measurements in infants and children. In Eur Respir Mon Volume 31 . Eur Respir Mon; 2006:166-194.

4. Godfrey S, Kamburoff PL, Nairn JR: Spirometry, lung volumes and airway resistance in normal children aged 5 to 18 years. $\mathrm{Br} J$ Dis Chest 1970, 64:15-24.

5. Arets HG, Brackel HJ, van der Ent CK: Forced expiratory manoeuvres in children: do they meet ATS and ERS criteria for spirometry? Eur Respir J 200I, I 8:655-660.

6. Larsen GL, Kang JK, Guilbert T, Morgan W: Assessing respiratory function in young children: Developmental considerations. J Allergy Clin Immunol 2005, I I 5:657-666.

7. Kanengiser S, Dozor AJ: Forced expiratory maneuvers in children aged 3 to 5 years. Pediatr Pulmonol I994, I 8: I44- I49.

8. Crenesse D, Berlioz M, Bourrier T, Albertini M: Spirometry in children aged 3 to 5 years: reliability of forced expiratory maneuvers. Pediatr Pulmonol 200I, 32:56-6I.

9. Klug B, Bisgaard H: Specific airway resistance, interrupter resistance, and respiratory impedance in healthy children aged 2-7 years. Pediatr Pulmonol I998, 25:322-33I.

10. Merkus PJ, Mijnsbergen JY, Hop WC, de Jongste JC: Interrupter resistance in preschool children: measurement characteristics and reference values. Am J Respir Crit Care Med 2001, 163:1350-1355.

II. Phagoo SB, Wilson NM, Silverman M: Evaluation of the interrupter technique for measuring change in airway resistance in 5-year-old asthmatic children. Pediatr Pulmonol 1995, 20:387-395.

12. Eigen H, Bieler H, Grant D, Christoph K, Terrill D, Heilman DK, Ambrosius WT, Tepper RS: Spirometric pulmonary function in healthy preschool children. Am J Respir Crit Care Med 200I, 1 63:619-623.

13. Nystad W, Samuelsen SO, Nafstad P, Edvardsen E, Stensrud T, Jaakkola J): Feasibility of measuring lung function in preschool children. Thorax 2002, 57:1021-1027.

14. Zapletal A, Chalupova J: Forced expiratory parameters in healthy preschool children (3-6 years of age). Pediatr Pulmonol 2003, 35:200-207.

15. Aurora P, Stocks J, Oliver C, Saunders C, Castle R, Chaziparasidis G, Bush A: Quality control for spirometry in preschool children with and without lung disease. Am J Respir Crit Care Med 2004, 169: II52-II59.

16. Miller MR, Hankinson J, Brusasco V, Burgos F, Casaburi R, Coates A, Crapo R, Enright P, van der Grinten CP, Gustafsson P, Jensen R, Johnson DC, Maclntyre N, McKay R, Navajas D, Pedersen OF, Pellegrino R, Viegi G, Wanger J: Standardisation of spirometry. Eur Respir J 2005, 26:319-338.

17. Griner PF, Mayewski RJ, Mushlin AI, Greenland P: Selection and interpretation of diagnostic tests and procedures. Principles and applications. Ann Intern Med 1981, 94:557-592.

18. Asthma and respiratory symptoms in 6-7 yr old Italian children: gender, latitude, urbanization and socioeconomic factors. SIDRIA (Italian Studies on Respiratory Disorders in Childhood and the Environment). Eur Respir J 1997, I 0:1780-1786.

19. International Study of Asthma and Allergies in Childhood Edited by: Auckland B. ISAAC Coordinating Committee; 1992.

20. Standardization of Spirometry, 1994 Update. American Thoracic Society. Am J Respir Crit Care Med 1995, I 52: I I07-I I 36.

21. Miller MR, Crapo R, Hankinson J, Brusasco V, Burgos F, Casaburi R, Coates A, Enright P, Grinten CPM, Gustafsson P, Jensen R, Johnson DC, Maclntyre N, McKay R, Navajas D, Pedersen OF, Pellegrino R, Viegi G, Wanger J: General considerations for lung function testing. Eur Respir J 2005, 26:153-161.

22. Fox J: Applied Regression Analysis, Linear Models and Related Methods. SAGE; 1994.

23. National Health and Nutrition Examination Survey:2000 CDC Growth Charts 2006 [http://www.cdc.gov/growthcharts/]. National Center for Centers for Disease Control and Prevention
24. Wang X, Dockery DW, Wypij D, Fay ME, Ferris BG Jr.: Pulmonary function between 6 and 18 years of age. Pediatr Pulmonol 1993, I 5:75-88.

25. Jones $\mathrm{MH}$, Howard J, Davis S, Kisling J, Tepper RS: Sensitivity of spirometric measurements to detect airway obstruction in infants. Am J Respir Crit Care Med 2003, I 67:1283-I 286.

26. Tepper RS, Jones M, Davis S, Kisling J, Castile R: Rate constant for forced expiration decreases with lung growth during infancy. Am J Respir Crit Care Med 1999, 160:835-838.

27. Vilozni D, Barker M, Jellouschek H, Heimann G, Blau H: An interactive computer-animated system (SpiroGame) facilitates spirometry in preschool children. Am J Respir Crit Care Med 200I, 164:2200-2205.

28. Gracchi V, Boel M, van der LJ, van der Ent CK: Spirometry in young children: should computer-animation programs be used during testing? Eur Respir J 2003, 21 :872-875.

29. Marostica PJ, Weist AD, Eigen H, Angelicchio C, Christoph K, Savage J, Grant D, Tepper RS: Spirometry in 3- to 6-year-old children with cystic fibrosis. Am J Respir Crit Care Med 2002, 166:67-7I.

30. Quanjer PH, Tammeling G], Cotes JE, Pedersen OF, Peslin R, Yernault JC: Lung volumes and forced ventilatory flows. Report Working Party Standardization of Lung Function Tests, European Community for Steel and Coal. Official Statement of the European Respiratory Society. Eur Respir J Suppl 1993, 16:5-40.

31. Obesity: preventing and managing the global epidemic. Report of a WHO consultation. World Health Organ Tech Rep Ser 2000, 894:i-253.

32. Pistelli F, Bottai M, Viegi G, Di PF, Carrozzi L, Baldacci S, Pedreschi M, Giuntini C: Smooth reference equations for slow vital capacity and flow-volume curve indexes. Am J Respir Crit Care Med 2000, | 6 |:899-905.

33. Lebowitz MD, Holberg CJ, Knudson RJ, Burrows B: Longitudinal study of pulmonary function development in childhood, adolescence, and early adulthood. Development of pulmonary function. Am Rev Respir Dis 1987, I36:69-75.

34. Mitra AD, Ogston S, Crighton A, Mukhopadhyay S: Lung function and asthma symptoms in children: relationships and response to treatment. Acta Paediatr 2002, 91:789-792.

35. Bacharier LB, Strunk RC, Mauger D, White D, Lemanske RF Jr., Sorkness $C A$ : Classifying asthma severity in children: mismatch between symptoms, medication use, and lung function. $\mathrm{Am} J$ Respir Crit Care Med 2004, I 70:426-432.

Publish with Biomed Central and every scientist can read your work free of charge

"BioMed Central will be the most significant development for disseminating the results of biomedical research in our lifetime. "

Sir Paul Nurse, Cancer Research UK

Your research papers will be:

- available free of charge to the entire biomedical community

- peer reviewed and published immediately upon acceptance

- cited in PubMed and archived on PubMed Central

- yours - you keep the copyright
BiolMedcentral 